\title{
Tratamento de esgoto sanitário em reator híbrido em bateladas sequenciais: eficiência e estabilidade na remoção de matéria orgânica e nutrientes (N, P)
}

\section{Sewage treatment in a sequencing batch hybrid reactor: efficiency and stability in organic matter and nutrient (N, $\mathrm{P}$ ) removal}

\author{
Luiz Gonzaga Lamego Neto \\ Engenheiro Sanitarista e Ambiental. Mestre em Engenharia Ambiental pela Universidade Federal de Santa Catarina (UFSC)
}

\section{Rejane Helena Ribeiro da Costa}

Engenheira Civil. Mestre em Hidráulica e Saneamento pela Escola de Engenharia de São Carlos da Universidade de São Paulo (USP). Doutora pelo Institut National des Sciences Appliquées (INSA), Toulouse, França. Professora Titular do Departamento de Engenharia Sanitária e Ambiental da UFSC. Pesquisadora Categoria $1 \mathrm{~B}$ do CNPq

\section{Resumo}

Este trabalho apresenta os resultados de estudo sobre o comportamento de um reator híbrido, operado em bateladas sequenciais, na remoção conjunta de matéria carbonácea, nitrogênio e fósforo de esgoto sanitário. Operado em ciclos de 8 horas de duração, o reator possuía em seu interior um suporte fixo com rede

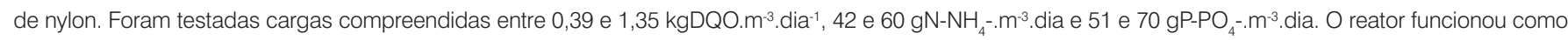
um sistema estável e apresentou boas condições de depuração. A remoção da matéria carbonácea mostrou-se elevada, com eficiências médias de $92 \%$ de $\mathrm{DBO}_{5}$ e 80\% de DQO. A remoção de nutrientes variou entre 59 e 71\% para nitrogênio total e entre 45 e 67\% para fósforo total. Tanto no lodo em suspensão, quanto no biofilme, foi observada a ocorrência de bactérias oxidadoras de amônio e micro-organismos responsáveis pela desnitrificação e remoção biológica de fósforo.

Palavras-chave: esgoto sanitário; desnitrificação; nitrificação; remoção biológica de fósforo; reator híbrido em bateladas sequenciais.

\begin{abstract}
This paper presents the results about the behavior of a sequencing batch hybrid reactor on combined removal of carbonaceous matter, nitrogen and phosphorus from sewage. Operated in 8-hour cycles, the reactor had a nylon net fixed inside. Loads between 0.39 and 1.35 kg COD. ${ }^{-3} \cdot$ day $^{-1}, 42{\text { and } 60 ~ \mathrm{gN}^{-} \mathrm{NH}_{4}-\mathrm{m}^{-3} \text {. day }}^{-1}$

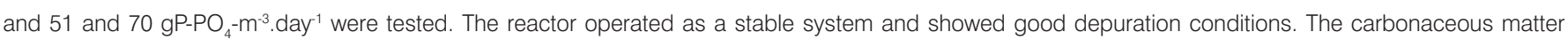
removal was high, with 92 and $80 \%$ efficiencies average to $\mathrm{BOD}_{5}$ and $\mathrm{COD}$, respectively. The nutrients removal varied between 59 and $71 \%$ for total nitrogen and between 45 and $67 \%$ for total phosphorus. In both, sludge in suspension and the biofilm, occurrence of ammonium-oxidizing bacteria and microorganisms responsible for denitrification and biological phosphorus removal was observed.
\end{abstract}

Keywords: sewage; denitrification; nitrification; biological phosphorus removal; hybrid sequencing batch reactor.

\section{Introdução}

No Brasil, as estações de tratamento de efluentes (ETEs), em geral, têm sido projetadas para remover sólidos sedimentáveis e matéria orgânica carbonácea, havendo deficiências na remoção de nutrientes (nitrogênio e fósforo), que são causadores da deterioração dos recursos hídricos, acelerando a eutrofização dos corpos d'água receptores dos efluentes.

Visando à remoção do nitrogênio das águas residuárias, tem-se estudado extensivamente o processo biológico de nitrificação e desnitrificação. O desafio em se projetar um reator capaz de remover o nitrogênio do esgoto está na utilização da matéria orgânica carbonácea do próprio esgoto necessária para ocorrência do processo de desnitrificação, evitando, assim, a necessidade de adição de uma fonte externa de carbono.

A remoção de fósforo por via biológica ocorre quando micro-organismos específicos fósforo-acumuladores (Acinetobacter, Pseudomonas, Aerobacter, $\alpha$ - e $\beta$-proteobactérias, por exemplo) assimilam fósforo, o qualentra na composição de várias macromoléculas 
no interior das células, sendo armazenado como polifosfato (WU et al., 2009). Para que esse fenômeno aconteça é necessário que os reatores biológicos apresentem zonas/fases anaeróbias-aeróbias. $\mathrm{Na}$ fase anaeróbia, os micro-organismos ficam sob intenso estresse podendo ocorrer a relargagem do fósforo acumulado nas células. $\mathrm{Na}$ fase aeróbia ocorre o consumo exagerado de fósforo (luxury uptake) pelos micro-organismos que foram submetidos ao estresse na fase anaeróbia (MACHNICKA; GRÜBEL; SUSCHKA, 2008).

Para que esses processos biológicos ocorram com eficiência, têm-se aprimorado as ETEs para que realizem conjuntamente a remoção de carbono e nutrientes numa mesma unidade operacional. Uma das soluções adotadas consiste na utilização de um único tanque, que atua como reator biológico e decantador, funcionando em ciclos, que compreendem fases de enchimento, reações biológicas, decantação e repouso, chamado de reator de bateladas sequenciais (RBS). A remoção combinada de carbono e de nutrientes é realizada de acordo com as condições estabelecidas para as fases (aeróbias/anóxicas) dos ciclos (ARTAN e ORHON, 2005). Lin e Jing (2001) estudaram o enchimento escalonado e reações biológicas em fases alternadas anóxicas/ aeróbias de um reator RBS, cujos resultados mostraram que o tratamento do efluente (esgoto sintético) melhorou comparativamente a um reator com um único enchimento. Isso se deve ao esgoto afluente apresentar compostos orgânicos carbonáceos e alcalinidade, o que permitiu a ocorrência do processo de desnitrificação e nitrificação, resultando em remoção de nitrogênio total em média de 90\%.

Outra solução apresentada recentemente para aperfeiçoar o desempenho dos reatores de tratamento de esgoto é a combinação de biomassa suspensa e fixa num único sistema. São chamados de "reatores híbridos", permitindo instalações mais compactas, menores custos construtivos e, principalmente, a remoção de nitrogênio e fósforo, efetuando um tratamento mais completo do esgoto (WOLFF; PAUL; COSTA, 2005). O material suporte utilizado nesses reatores é bastante variado, citam-se como exemplo: esferas de álcool polivinílico - PVA em gel (LEVSTEK e PLAZL, 2009); esferas de polietileno e plástico reciclado (ØDEGAARD, 2006; PAUL et al,. 2007); e fitas plásticas, espumas de poliuretano, rede de nylon e cascas de ostras (SOUTO, 2007).

Neste trabalho é apresentado o estudo do tratamento de esgoto sanitário utilizando um reator híbrido em bateladas sequenciais (RHBS), que consiste num reator de lodo ativado com adição de um suporte fixo de rede de nylon, operando em bateladas sequenciais e com enchimento escalonado. O objetivo desta pesquisa foi avaliar o processo de tratamento quanto à remoção conjunta de carbono, nitrogênio e fósforo, sob diferentes cargas aplicadas.

\section{Material e métodos}

$\mathrm{O}$ esgoto bruto utilizado na pesquisa era proveniente da rede coletora de esgotos da cidade de Florianópolis (SC), operada pela Companhia Catarinense de Águas e Saneamento (CASAN). A captação era realizada por um conjunto moto-bomba (Schneider, BSC-94 - 3/4 CV Mono $60 \mathrm{~Hz}$ ) instalado dentro de um poço de visita, de onde o esgoto era bombeado para um tanque de armazenamento com volume de $5 \mathrm{~m}^{3}$ e tempo de retenção hidráulica (TRH) entre 1 e 2 dias. A partir dessa unidade, o esgoto bruto era bombeado para o reator biológico (RHBS), por meio de bomba centrífuga $\left(\right.$ Netzsch $^{\circledR}$ ), onde eram processados os ciclos operacionais. Cada ciclo era composto por cinco fases distintas: enchimento, reação anóxica, reação aeróbia, decantação e retirada, sendo que as três primeiras fases eram repetidas três vezes sequencialmente antes da decantação, conforme esquemas apresentados na Figura 1.

O RHBS tinha forma cilíndrica, fabricado com chapa de ferro de $5 \mathrm{~mm}$ de espessura, tendo altura de 2,20 m e diâmetro de 0,95 m. Uma altura útil de $2 \mathrm{~m}$ foi utilizada para o tratamento, que significa
1 - Esgoto bruto (PV CASAN)

2 - Bomba submersa

3 - TUbulação de proteção

4 - Tanque de armazenamento

5 - Bomba centrífuga (retirada)

6 - Bomba centrífuga (enchimento)

7 - Painel de controle elétrico

8 - RHBS

9 - Bóias de nível

10 - Esgoto em tratamento

11 - Suporte fixo (rede de nylon)

12 - Membranas circulares

13 - Compressor de ar

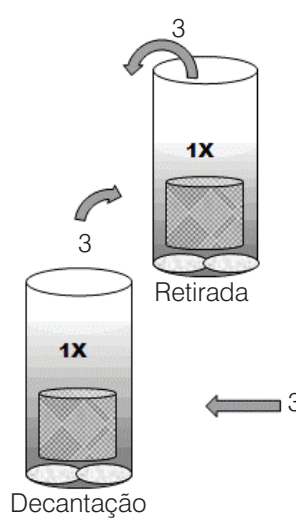

123

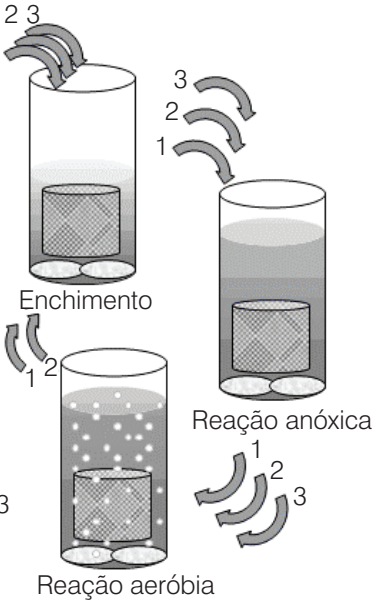

Figura 1 - Esquema do sistema de tratamento e esquema do funcionamento de um ciclo do reator híbrido em bateladas sequenciais. 
um volume máximo de $1,43 \mathrm{~m}^{3}$. Na base do reator, foram instalados dois difusores de ar do tipo membrana circular, de diâmetro de 0,20 m cada uma, alimentado por um compressor de ar (Air Pump, Modelo EL-100) com capacidade de 100 L. min'-1. O reator foi operado de forma automatizada com o controle do tempo de cada fase de ciclo por meio de um CLP (Controlador Microprocessador, Siemens) localizado no interior de um painel de comandos elétricos e gerenciado por um software WinDosPs.

No interior do reator, foi adicionado um suporte de rede de nylon para adesão da biomassa, que foi fixado em uma armação de aço inoxidável de 0,85 m de altura e 0,75 m de diâmetro, que ocupavam em torno de $40 \%$ da altura útil do reator. Esse material foi escolhido entre os materiais testados no estudo de reatores híbridos em fluxo contínuo, realizado por Souto (2007), devido ao seu melhor desempenho no tratamento de esgoto, à alta resistência e à elevada superfície específica. A rede de nylon possuía densidade ( $\rho)$ de $569 \mathrm{~kg} . \mathrm{m}^{-3}$, com área superficial específica de $4140 \mathrm{~m}^{2} \cdot \mathrm{m}^{-3}$ de suporte.

Para cada ciclo padrão foram adotados os tempos: 6 a 10 minutos de enchimento, 60 minutos para cada fase de reação anóxica e 70 minutos para cada fase de reação aeróbia, com enchimento sempre na fase anóxica. Os tempos de decantação e de retirada eram, respectivamente, de 40 e de 20 minutos. Cada ciclo, então, totalizava 8 horas, ocorrendo 3 ciclos por dia. Eram tratados 540 L de efluente por ciclo e $1.620 \mathrm{~L}$ por dia.

O estudo do RHBS, que foi realizado de fevereiro a dezembro de 2007, foi dividido em três etapas conforme variação das cargas aplicadas (Tabela 1). Nas Etapas II e III foi adicionada uma solução de acetato de sódio $\left(\mathrm{CH}_{3} \mathrm{COOHNa}\right)$ com objetivo de aumentar a carga orgânica na entrada do reator. Nas Etapas I e III, uma solução de carbonato de cálcio foi adicionada no início do ciclo, para garantir alcalinidade suficiente ao desenvolvimento da nitrificação, conforme recomendado por von Sperling (2002). As análises realizadas e seus respectivos métodos, cuja maioria seguiu o Standard Methods (APHA; AWWA; WEF, 2005), estão listados na Tabela 2.

\section{Cálculos realizados}

\section{Eficiência}

As eficiências (E) de remoção, para as variáveis: $\mathrm{DQO}, \mathrm{N}_{-} \mathrm{NH}_{4}^{-}$ (nitrificação), $\mathrm{NTK}, \mathrm{DBO}_{5}, \mathrm{P}_{\mathrm{T}}$ e $\mathrm{P}_{-} \mathrm{PO}_{4^{-}}$, foram calculadas pela Equação 1 .

$E=\left(\frac{S_{O}-S_{S}}{S_{O}}\right) * 100$

Equação 1

Onde:

E: eficiência de remoção (\%);

$S_{0}$ : concentração afluente (esgoto bruto) $\left(\mathrm{mg} . \mathrm{L}^{-1}\right)$;

Ss: concentração efluente no final do ciclo (mg. $\left.\mathrm{L}^{-1}\right)$.
Tabela 1 - Síntese do tempo das etapas e cargas volumétricas aplicadas

\begin{tabular}{|c|c|c|c|}
\hline \multirow{2}{*}{ Parâmetros } & \multicolumn{3}{|c|}{ Etapas } \\
\hline & I & II & III \\
\hline Tempo da etapa (dia) & 175 & 18 & 59 \\
\hline $\mathrm{CV}_{\mathrm{DQO}}\left(\mathrm{kgDQO} \cdot \mathrm{m}^{-3} \cdot \mathrm{dia}^{-1}\right)$ & $0,39 \pm 0,13$ & $1,35 \pm 0,30$ & $0,71 \pm 0,15$ \\
\hline $\mathrm{CV}_{\mathrm{CH} 3 \mathrm{COOHNa}}\left(\mathrm{kgDQO} \cdot \mathrm{m}^{-3} \cdot \mathrm{dia}^{-1}\right)$ & - & 1,18 & 0,39 \\
\hline $\mathrm{CV}_{\mathrm{NH} 4}\left(\mathrm{gNH}_{4}-\mathrm{N} \cdot \mathrm{m}^{-3} \cdot \mathrm{dia}^{-1}\right)$ & $60 \pm 10$ & $42 \pm 11$ & $46 \pm 6,1$ \\
\hline $\mathrm{CV}_{\mathrm{PT}}\left(\mathrm{gPO}_{4}-\mathrm{P} \cdot \mathrm{m}^{-3} \cdot \mathrm{dia}^{-1}\right)$ & $70 \pm 30$ & $59 \pm 4,6$ & $51 \pm 10$ \\
\hline
\end{tabular}

Tabela 2 - Síntese das análises e métodos analíticos utilizados no monitoramento do reator reator híbrido em bateladas sequenciais

\begin{tabular}{|c|c|}
\hline Variáveis & Método \\
\hline $\mathrm{OD}\left(\mathrm{mg} \cdot \mathrm{L}^{-1}\right) ;$ temperatura $\left({ }^{\circ} \mathrm{C}\right) ; \mathrm{pH}$ & Sonda multiparâmetros (YSI 5562) \\
\hline $\mathrm{DBO}_{5}\left(\mathrm{mg} \cdot \mathrm{L}^{-1}\right)$ & Manométrico (SM 5210 D) \\
\hline $\mathrm{DQO}\left(\mathrm{mg} \cdot \mathrm{L}^{-1}\right)$ & $\begin{array}{l}\text { Colorimétrico - refluxo fechado } \\
\text { (SM 5220D) }\end{array}$ \\
\hline SST e SSV (mg. L-1) $^{-1}$ & $\begin{array}{l}\text { Gravimétrico após filtração em mem- } \\
\text { brana de acetato de celulose } 0,45 \mu \mathrm{m} \\
\text { (SM 2540D) }\end{array}$ \\
\hline ST, SF e SV $\left(m g \cdot L^{-1}\right)$ & Gravimétrico (SM 2540 B, E) \\
\hline $\mathrm{N}-\mathrm{NH}_{4}-$ e NTK $\left(\mathrm{mg} \cdot \mathrm{L}^{-1}\right)$ & $\begin{array}{l}\text { Destilação Kjeldahl (SM 4500-NH3-B } \\
\text { e 4500-Norg B) }\end{array}$ \\
\hline $\mathrm{N}-\mathrm{NO}_{2}{ }^{-}, \mathrm{N}-\mathrm{NO}_{3}-, \mathrm{P}-\mathrm{PO}_{4}{ }^{-}\left(\mathrm{mg} \cdot \mathrm{L}^{-1}\right)$ & $\begin{array}{l}\text { Cromatografia de íons (DIONEX 120) } \\
\text { (SM 4110C) }\end{array}$ \\
\hline$P_{T}\left(m g \cdot L^{-1}\right)$ & Colorimétrico (SM 4500- PB e 4500-PC) \\
\hline Análise FISH & Sondas específicas (AMANN, 1995) \\
\hline Microscopia ótica & Microscópio Olympus BX 40 \\
\hline Alcalinidade total $\left(\mathrm{mgCaCO}_{3} \cdot \mathrm{L}^{-1}\right)$ & Método titulométrico (SM 2320B) \\
\hline
\end{tabular}

$\mathrm{DBO}_{5}$ : demanda bioquímica de oxigênio; DQO: demando química de oxigênio; SST: Sólidos suspensos totais; SSV: sólidos suspensos voláteis; ST: sólidos totais; SF: sólidos fixos;

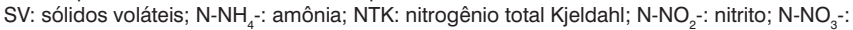
nitrato; $\mathrm{P}_{-} \mathrm{PO}_{4}-$ : fosfato; $\mathrm{P}_{\mathrm{T}}$ : fósforo total.

\section{Eficiência de desnitrificação}

A eficiência da desnitrificação $\left(E_{D N}\right)$ foi calculada utilizando-se a Equação 2.

$E_{\mathrm{DN}}=\left(\frac{\left(\left(\mathrm{N}-\mathrm{NH}_{4}-\right)_{\mathrm{E}}-\left(\mathrm{N}-\mathrm{NH}_{4}-\right)_{\mathrm{S}}\right)-\left(\mathrm{N}-\mathrm{NO}_{\mathrm{X}}-\right)_{\mathrm{S}}}{\left(\left(\mathrm{N}-\mathrm{NH}_{4}-\right)_{\mathrm{E}}-\left(\mathrm{N}-\mathrm{NH}_{4}-\right)_{\mathrm{S}}\right)}\right) * 100 \quad$ Equação 2

Onde:

$E_{\mathrm{DN}}$ : eficiência de desnitrificação (\%);

$\left(\mathrm{N}-\mathrm{NH}_{4}{ }^{-}\right)_{\mathrm{E}}$ : concentração do amônio afluente $\left(\mathrm{mg} \cdot \mathrm{L}^{-1}\right)$;

$\left(\mathrm{N}-\mathrm{NH}_{4}^{-}\right)_{5}$ : concentração remanescente de amônio no efluente $\left(\mathrm{mg} . \mathrm{L}^{-1}\right)$;

$\left(\mathrm{N}-\mathrm{NO}_{\mathrm{x}}\right)_{\mathrm{s}}$ : concentração dos compostos de nitrogênio oxidado (nitrito e nitrato) no final do ciclo (mg. $\left.\mathrm{L}^{-1}\right)$.

\section{Eficiência de remoção do nitrogênio total}

A eficiência de remoção do nitrogênio total $\left(E_{\mathrm{NT}}\right)$ foi calculada utilizando-se a Equação 3.

$\mathrm{E}_{\mathrm{NT}}=\left(\frac{(\mathrm{NT})_{0}-(\mathrm{NT})_{\mathrm{F}}}{(\mathrm{NT})_{0}}\right) * 100$

Equação 3 
Onde:

$E_{\mathrm{NT}}$ : eficiência de remoção do nitrogênio total (\%);

$N T_{0}$ : nitrogênio total no início do ciclo (concentrações no início do ciclo de $\mathrm{N}-\mathrm{NH}_{4}-($ ou NTK$\left.)+\mathrm{N}^{-N_{2}}{ }_{2}^{-}+\mathrm{N}^{-\mathrm{NO}_{3}}{ }^{-}\right)\left(\mathrm{mg} \cdot \mathrm{L}^{-1}\right)$;

$N T_{\mathrm{F}}$ : nitrogênio total no final do ciclo (concentrações no final do ciclo de $\mathrm{N}_{-\mathrm{NH}_{4}-}($ ou NTK$\left.)+\mathrm{N}_{-} \mathrm{NO}_{2}-+\mathrm{N}^{-\mathrm{NO}_{3}}{ }^{-}\right)\left(\mathrm{mg} \cdot \mathrm{L}^{-1}\right)$.

\section{Resultados e discussão}

Os valores médios obtidos com as leituras na fase anóxica e aeróbia pela sonda YSI 5562, para o oxigênio dissolvido (OD), temperatura e pH, em cada etapa do estudo, estão apresentados na Tabela 3.

As temperaturas médias nas fases anóxica e aeróbia ficaram em torno de $22^{\circ} \mathrm{C}$ nas Etapas I e II, e em torno de $25^{\circ} \mathrm{C}$ na Etapa III, conforme observado na Tabela 3. Quanto a fase anóxica, a temperatura manteve-se dentro da faixa ótima de 10 a $30^{\circ} \mathrm{C}$ para o processo de desnitrificação, de acordo com Henze et al. (1995). Entretanto, na fase aeróbia, a temperatura ficou fora da faixa ideal de 30 a $35^{\circ} \mathrm{C}$ para ocorrência da nitrificação, segundo esses autores, embora essa atividade biológica possa ocorrer numa faixa entre 4 a $45^{\circ} \mathrm{C}$ (UNITED STATES ENVIRONMENTAL PROTECTION AGENCY, 1993). Vários autores, no entanto, reportam eficiente nitrificação em reatores híbridos funcionando com temperaturas entre 16 e $20^{\circ} \mathrm{C}$ (MAAS; PARKER; LEGGE, 2008; PAUL et al., 2007).

Quanto ao OD, durante as fases anóxicas, as concentrações ficaram 92\% inferiores a $1 \mathrm{mg} . \mathrm{L}^{-1}$, ideal para que ocorra desnitrificação (HENZE et al., 2001). Durante as fases aeróbias, nas Etapas I e III as concentrações variaram entre 4 e $6 \mathrm{mg} . \mathrm{L}^{-1}$. Enquanto que na Etapa II, a média foi de 0,16 mg.L-1, valor inferior ao mínimo recomendado por Rittmann e McCarty (2001) de 2,0 mg.L-1 para a ocorrência de nitrificação. Esse comportamento se deve ao aumento da carga aplicada, com a adição de acetato de sódio $\left(\mathrm{CH}_{3} \mathrm{COOHNa}\right)$ no efluente bruto, ocasionando um rápido e contínuo aumento de sólidos no reator, sem que a retirada de lodo excedente fosse suficiente para manter o limite máximo de $3.500 \mathrm{mg} \cdot \mathrm{L}^{-1}$ indicado pela United States Environmental Protection Agency (1993). Essa falta de equilíbrio causou o aumento do nível da manta de lodo e o consumo excessivo do OD pela biomassa crescente, prejudicando a transferência de oxigênio no líquido e a sedimentação do lodo na fase de decantação.

$\mathrm{O}$ pH do efluente bruto apresentou média de 6,62, porém manteve-se maior nas fases seguintes devido à adição de carbonato de cálcio (Etapas I e III) e à mistura do efluente remanescente (Etapa II), no interior do reator. As concentrações médias de $\mathrm{pH}$ na fase aeróbia foram

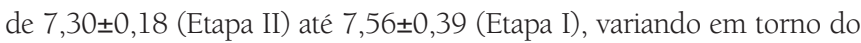
valor mínimo da faixa ideal de 7,5 a 8,0, recomendado por Metcalf $\&$ Eddy (2003) para a ocorrência do processo de nitrificação.

A retirada de lodo em excesso foi realizada pelo controle dos valores de SSV no reator, adotando-se um limite máximo de $3.500 \mathrm{mg} . \mathrm{L}^{-1}$, indicado por United States Environmental Protection Agency (1993) para reatores em bateladas sequenciais. A idade do lodo teve média de 20 dias nas Etapas I e III com boa sedimentabilidade do lodo, valor também recomendado por United States Environmental Protection Agency (1993). Na Etapa II, a idade do lodo teve média de 9 dias devido à perda de SSV no efluente final, que ocorreu em função do aumento de carga no esgoto bruto e consequente aumento do SSV no reator, ocasionando um desequilíbrio no sistema e saída de sólidos no efluente final.

No Brasil, adota-se a idade de lodo na faixa de 4 a 10 dias para sistemas de lodo ativado convencional. Porém, pesquisas realizadas por Callado e Foresti (2002) e Santos (2005) mostraram que reatores em batelada sequenciais podem ser operados com idades de lodo maiores mantendo-se alta eficiência na remoção de DBO e nutrientes, isto porque a idade do lodo depende da natureza do efluente bruto e das condições operacionais do sistema de tratamento. Ainda segundo Santos, Cybis e Gehling (2005), o reator operado em bateladas sequenciais é capaz de suportar variações na concentração de sólidos suspensos voláteis, na composição do esgoto bruto e na taxa de consumo de oxigênio sob diferentes idades do lodo sem comprometer a qualidade do efluente final.

\section{Remoção de matéria carbonácea}

Os resultados obtidos nas três etapas do estudo para a $\mathrm{DQO}, \mathrm{DBO}_{5} \mathrm{e}$ relação SSV/SST no interior do reator estão apresentados na Tabela 4.

Tabela 3 - Resultados (valores médios e desvio padrão) obtidos para oxigênio dissolvido, temperatura e pH nas etapas do estudo

\begin{tabular}{lcccc} 
Fase & $\begin{array}{c}\text { Etapa }(\mathrm{n}=\text { número } \\
\mathrm{de} \text { amostras) }\end{array}$ & $\mathrm{OD}\left(\mathrm{mg} \cdot \mathrm{L}^{-1}\right)$ & $\mathrm{T}\left({ }^{\circ} \mathrm{C}\right)$ & $\mathrm{pH}$ \\
Fase & $\mathrm{I}(\mathrm{n}=144)$ & $0,53 \pm 0,85$ & $22,23 \pm 4,49$ & $7,31 \pm 0,40$ \\
\cline { 2 - 5 } anóxica & $\mathrm{II}(\mathrm{n}=22)$ & $0,12 \pm 0,13$ & $21,80 \pm 0,92$ & $7,19 \pm 0,33$ \\
\cline { 2 - 5 } & $\mathrm{III}(\mathrm{n}=44)$ & $0,25 \pm 0,60$ & $25,49 \pm 0,74$ & $7,26 \pm 0,43$ \\
Fase & $\mathrm{I}(\mathrm{n}=147)$ & $5,51 \pm 1,79$ & $22,95 \pm 5,28$ & $7,56 \pm 0,39$ \\
aeróbia & $\mathrm{II}(\mathrm{n}=21)$ & $0,16 \pm 0,17$ & $22,43 \pm 1,12$ & $7,30 \pm 0,18$ \\
& $\mathrm{III}(\mathrm{n}=42)$ & $3,96 \pm 1,11$ & $25,92 \pm 0,85$ & $7,37 \pm 0,44$
\end{tabular}

OD: oxigênio dissolvido.

Tabela 4 - Resultados dos parâmetros de matéria carbonácea ( $n=$ número de amostras)

\begin{tabular}{|c|c|c|c|c|}
\hline Parâmetro & & Etapa I & Etapa II & Etapa III \\
\hline \multirow{3}{*}{$\begin{array}{l}\text { DQO } \\
\left(\mathrm{mg} \cdot \mathrm{L}^{-1}\right)\end{array}$} & Entrada & $352 \pm 119(n=57)$ & $1.234 \pm 278(n=6)$ & $649 \pm 139(n=15)$ \\
\hline & Saída & $57 \pm 42(n=55)$ & $232 \pm 80(n=6)$ & $121 \pm 38(n=15)$ \\
\hline & \% Remoção & $84 \pm 8,8(n=55)$ & $80 \pm 9(n=6)$ & $80 \pm 7,5(n=15)$ \\
\hline \multirow{3}{*}{$\begin{array}{l}\mathrm{DBO}_{5} \\
\left(\mathrm{mg} \cdot \mathrm{L}^{-1}\right)\end{array}$} & Entrada & $269 \pm 126(n=14)$ & $915 \pm 89(n=2)$ & $462 \pm 32(n=5)$ \\
\hline & Saída & $17 \pm 11(n=14)$ & $42 \pm 28(n=2)$ & $35 \pm 15(n=5)$ \\
\hline & \% Remoção & $92 \pm 8(n=15)$ & $95 \pm 3,5(n=2)$ & $92 \pm 3,8(n=5)$ \\
\hline SSV/SST (\%) & Variação & 0,73 a 0,84 & 0,92 a 0,98 & 0,72 a 0,89 \\
\hline
\end{tabular}


Nas três etapas do estudo, a DQO teve remoção em torno de 80\%, com concentrações efluentes entre 15 e $315 \mathrm{mg} \cdot \mathrm{L}^{-1}$, enquanto a $\mathrm{DBO}_{5}$ teve remoção superior a $90 \%$, tendo o efluente final concentrações variando entre 10 e $70 \mathrm{mgDBO}_{5} \cdot \mathrm{L}^{-1}$. Na Etapa II, a concentração de $\mathrm{DBO}_{5}$ no efluente bruto apresentou média de 915 $\pm 89 \mathrm{mg}$. $\mathrm{L}^{-1}$ e uma eficiência média de remoção de 95 $\$ 3,5 \%$. Mesmo com o aumento da carga aplicada e a insuficiência de OD no reator para degradação de todo o substrato, o reator RHBS foi capaz de tratar o efluente.

O comportamento da matéria orgânica também foi avaliado pelos sólidos presentes no reator. Nas Etapas I e III, o efluente tratado apresentou concentrações médias de $23 \mathrm{mgSSV} . \mathrm{L}^{-1}$, com eficiência de remoção média entre 78 e $82 \%$ para SSV, indicando estabilidade do sistema biológico. A relação SSVISST do lodo variou entre 0,72 e 0,98, que caracteriza sistemas de lodo ativado convencional (METCALF \& EDDY, 2003). As concentrações de SSV no lodo foram de no máximo $3.500 \mathrm{mgSSV} . \mathrm{L}^{-1}$, valor dentro da faixa de 1.500-5.000 mg SSV.L ${ }^{-1}$ para lodo ativado convencional recomendado por von Sperlling (2002).

Na Etapa II observou-se o aumento das concentrações de sólidos no RHBS, ultrapassando o limite máximo de $5.000 \mathrm{mgSST}^{-L^{-1}}$, ocasionando assim prejuízo na transferência de oxigênio a toda biomassa e implicando numa área mais elevada de decantação. Como consequência, o efluente de saída do reator apresentou concentrações de $389 \pm 143$ mgSST.L ${ }^{-1}$, valor típico de um efluente ainda não tratado.

\section{Remoção de nitrogênio}

$\mathrm{Na}$ Tabela 5 estão apresentados os resultados obtidos para as frações nitrogenadas, do afluente e efluente, e os percentuais de desnitrificação, nitrificação e remoção do nitrogênio total, durante as etapas do estudo.

$\mathrm{Na}$ Etapa I, a remoção média de NT foi de $71 \%$, havendo nitrificação e desnitrificação com eficiência média de, respectivamente, 78 e 94\%. Observa-se na Figura 2 que alguns ciclos monitorados apresentaram eficiências menores na desnitrificação, em torno de 80\%, devido a uma baixa relação DQO/NTK. De acordo com Artan e Orhon (2005), o uso de enchimento escalonado em reator RBS é ideal para ocorrência da pré-desnitrificação quando a relação DQO/ NTK é $\geq 7$. Ressalta-se também que, apesar da eficiência alcançada na remoção de nitrogênio nos demais ciclos dessa etapa, observou-se a presença de nitrito no efluente tratado ( $\left.>1 \mathrm{mg} \cdot \mathrm{L}^{-1}\right)$, indicando que o processo de nitrificação não se dá até seu último estágio de oxidação. Ye et al. (2009) relatam que a remoção de nitrogênio via nitrito (nitrificação curta) em reatores RBS tem sido demonstrada com sucesso por muitos autores, reduzindo em cerca de $25 \%$ as necessidades de oxigênio para as reações aeróbias e 40\% das necessidades de DQO no estágio de desnitrificação.

$\mathrm{Na}$ Figura 3A estão apresentados os valores de compostos nitrogenados $\left(\mathrm{N}_{-} \mathrm{NH}_{4}^{-}, \mathrm{N}_{-} \mathrm{NO}_{2}-\mathrm{e} \mathrm{N}_{-} \mathrm{NO}_{3}^{-}\right.$) e na Figura $3 \mathrm{~B}$, os valores de $\mathrm{pH}$ e alcalinidade $\left(\mathrm{CaCO}_{3}\right)$, ao longo de um ciclo padrão monitorado na Etapa I. Analisando conjuntamente os resultados obtidos para $\mathrm{N}-\mathrm{NH}_{4}$ - e os valores de $\mathrm{pH}$, nessas figuras, verifica-se que, quando o processo de nitrificação se inicia na fase aeróbia (queda de $\mathrm{N}_{-} \mathrm{NH}_{4}^{-}$), o pH decresce, até o momento em que a nitrificação foi completada,

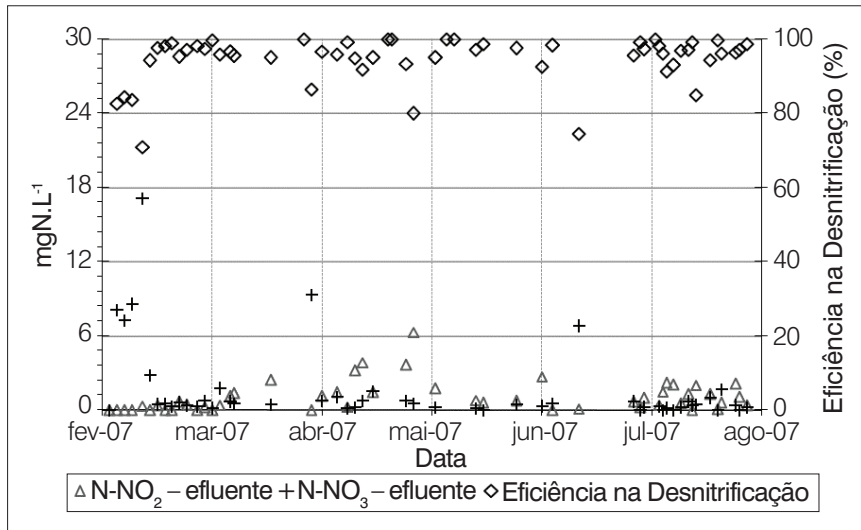

Figura $2-\mathrm{NO}_{3}-\mathrm{N}-, \mathrm{NO}_{2}-\mathrm{N}-$ no efluente tratado e eficiência na desnitrificação (Etapa I).

Tabela 5 - Concentrações médias e desvio padrão das frações nitrogenadas e percentuais obtidos na desnitrificação, nitrificação e remoção de nitrogênio total durante as etapas do estudo ( $\mathrm{n}=$ número de amostras)

\begin{tabular}{|c|c|c|c|}
\hline & Etapa I & Etapa II & Etapa III \\
\hline NTK entrada (mgN-NTK. L-1) & $65 \pm 12(n=54)$ & $54 \pm 14(n=6)$ & $46 \pm 5,7(n=15)$ \\
\hline NTK saída (mgN-NTK.L-1) & $14 \pm 11(n=54)$ & $14 \pm 3,4(n=6)$ & $6,5 \pm 5,2(n=15)$ \\
\hline Amônia entrada $\left(\mathrm{mgN}^{\left.-\mathrm{NH}_{4} \cdot \mathrm{L}^{-1}\right)}\right.$ & $60 \pm 12(n=51)$ & $39 \pm 10(n=6)$ & $42 \pm 5,6(n=15)$ \\
\hline Amônia saída $\left(\mathrm{mgN}-\mathrm{NH}_{4} \cdot \mathrm{L}^{-1}\right)$ & $13 \pm 10(n=51)$ & $10 \pm 3,4(n=6)$ & $5,4 \pm 4,6(n=15)$ \\
\hline Nitrito entrada $\left(\mathrm{mgN}-\mathrm{NO}_{2} \cdot \mathrm{L}^{-1}\right)$ & $<0,002(\mathrm{n}=51)$ & $<0,002(n=6)$ & $<0,002(n=15)$ \\
\hline Nitrito saída $\left(\mathrm{mgN}-\mathrm{NO}_{2} \cdot \mathrm{L}^{-1}\right)$ & $1,05 \pm 1,25(n=51)$ & $0,68 \pm 0,62(n=6)$ & $0,36 \pm 0,45(n=15)$ \\
\hline Nitrato entrada $\left(\mathrm{mgN}-\mathrm{NO}_{3} \cdot \mathrm{L}^{-1}\right)$ & $0,24 \pm 0,89(n=51)$ & $0,10 \pm 0,15(n=6)$ & $0,30 \pm 0,44(n=15)$ \\
\hline 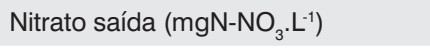 & $1,44 \pm 3,05(n=51)$ & $0,86 \pm 1,03(n=6)$ & $7,3 \pm 5,6(n=15)$ \\
\hline Desnitrificação - EDN (\%) & $94 \pm 6,4(n=50)$ & $93 \pm 3,6(n=6)$ & $80 \pm 13(n=15)$ \\
\hline Nitrificação - EN (\%) & $78 \pm 15(n=57)$ & $61 \pm 18(n=6)$ & $87 \pm 11(n=15)$ \\
\hline Remoção nitrogênio total - ENT (\%) & $71 \pm 14(n=49)$ & $59 \pm 13(n=6)$ & $69 \pm 6,5(n=14)$ \\
\hline
\end{tabular}



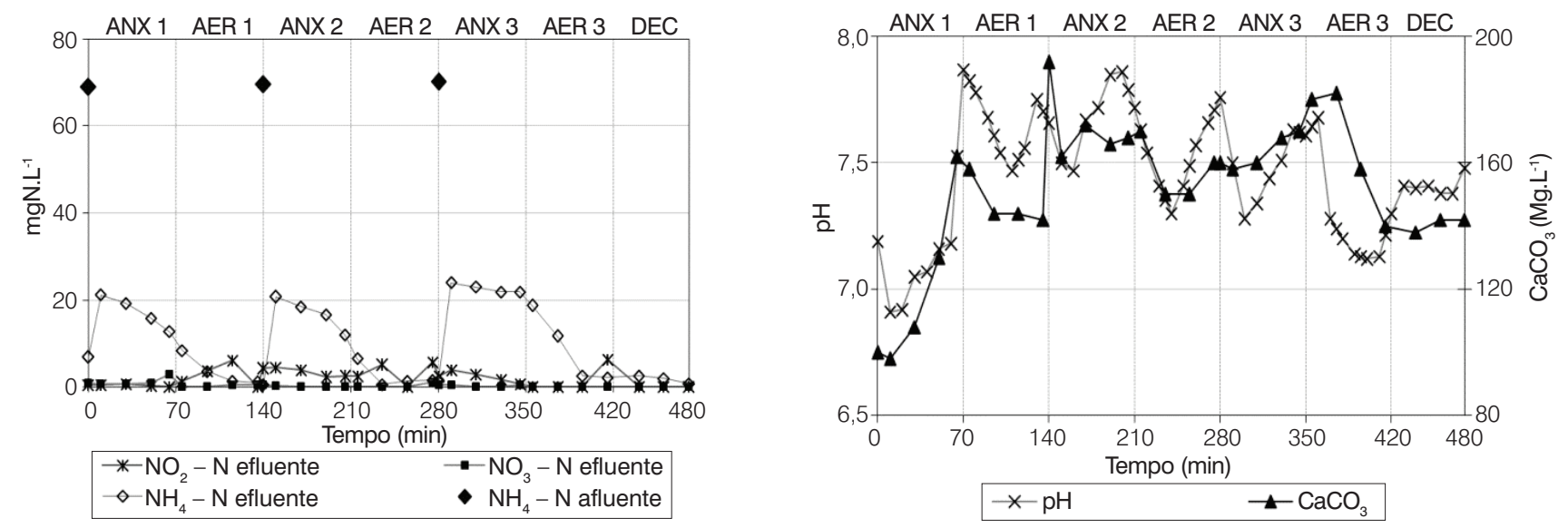

Figura 3 - (A) N-NO ${ }_{3}^{-}, \mathrm{N}_{-} \mathrm{NO}_{2}$ - e N-NH4- e (B) pH e alcalinidade ao longo de um ciclo padrão (Etapa I).

em seguida, observa-se um aumento do $\mathrm{pH}$, formando o característico "vale da amônia" citado na literatura (YE et al., 2009). A alcalinidade foi consumida nas fases aeróbias do ciclo devido à liberação do íon $\mathrm{H}^{+}$no processo de nitrificação, mas permaneceu acima de $140 \mathrm{mgCaCO}_{3} \cdot \mathrm{L}^{-1}$ devido à adição de cal, realizada no início da primeira fase aeróbia, ficando sempre acima do valor mínimo de $70 \mathrm{mgCaCO} 3 . \mathrm{L}^{-1}$, conforme recomendação de von Sperling (2002) para manter a biomassa estável em reator de lodo ativado. Durante as fases anóxicas (2 e 3), a alcalinidade foi recuperada por meio da desnitrificação, indicando a estabilidade do reator nos processos de nitrificação e desnitrificação, estando de acordo com Hoffmann et al. (2007).

$\mathrm{Na}$ Etapa II, a conversão de amônio a $\mathrm{N}^{-\mathrm{NO}_{2}}$ - e $\mathrm{N}^{-\mathrm{NO}_{3}}$ - (nitrificação) teve um percentual oscilando de 29 a $77 \%$, com média de $61 \pm 18 \%$. Entretanto, a eficiência da desnitrificação apresentou uma média de $93 \pm 3,6 \%$, semelhante à Etapa I. A remoção de nitrogênio total teve médias de $59 \pm 13 \%$. O efluente tratado apresentou uma concentração média de 14 $\pm 3,4$ mgNTK. $L^{-1}$ e 10 $\pm 3,4$ mgN-NH $4^{-}$. L $^{-1}$. Esses resultados indicam que o reator RHBS operou com desempenho inferior ao da Etapa I, porém satisfatório, no processo de remoção do nitrogênio total.

Na Figura 4 estão apresentados os resultados dos compostos de nitrogênio durante um ciclo padrão monitorado na Etapa II. Verifica-se que o amônio ficou próximo de $20 \mathrm{mg} \cdot \mathrm{L}^{-1}$ no final das fases aeróbias e no efluente tratado, indicando uma limitação na degradação desse composto. O excesso de carbono não oxidado, devido ao OD insuficiente, causou uma inibição na atividade microbiana dos micro-organismos nitrificantes. Observa-se baixa produção de $\mathrm{N}_{-} \mathrm{NO}_{2}$ - ou N-NO $\mathrm{N}_{3}$ - ao longo

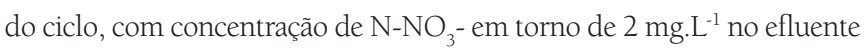
tratado. Nesse ciclo, a relação DQO/NTK estava em média de 25, que favorece a desnitrificação, conforme Rittmann e McCarty (2001).

$\mathrm{Na}$ Etapa III, a nitrificação e a desnitrificação tiveram eficiência média de, respectivamente, $87 \pm 11 \%$ e 80 $13 \%$. Em relação à remoção de nitrogênio total, a eficiência foi de $69 \pm 6,5 \%$. Na Figura 5 estão

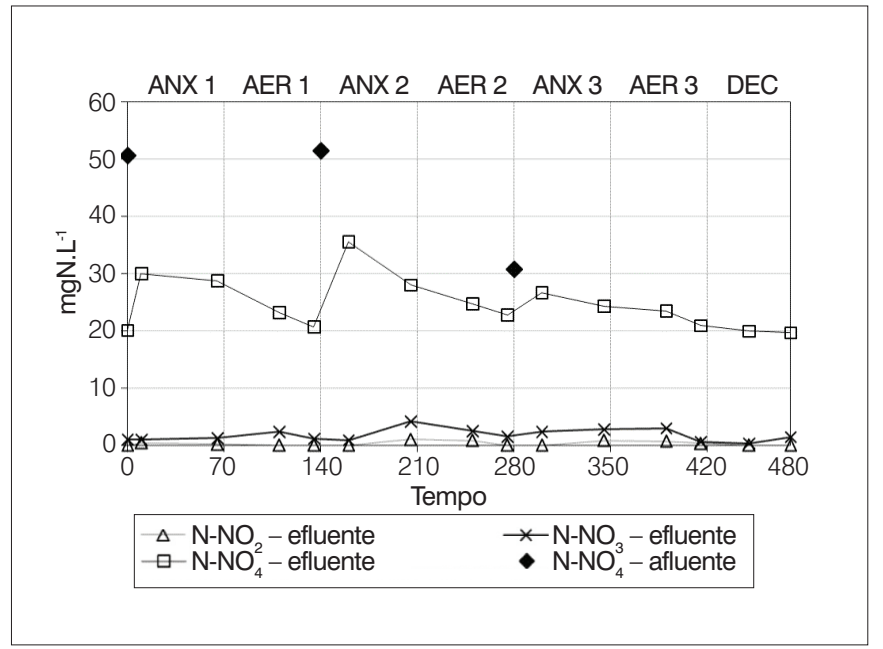

Figura 4 - N-NH - -, N-NO $\mathrm{N}_{3}$ - e N-NO $\mathrm{N}_{2}$ - ao longo de um ciclo padrão (Etapa II).

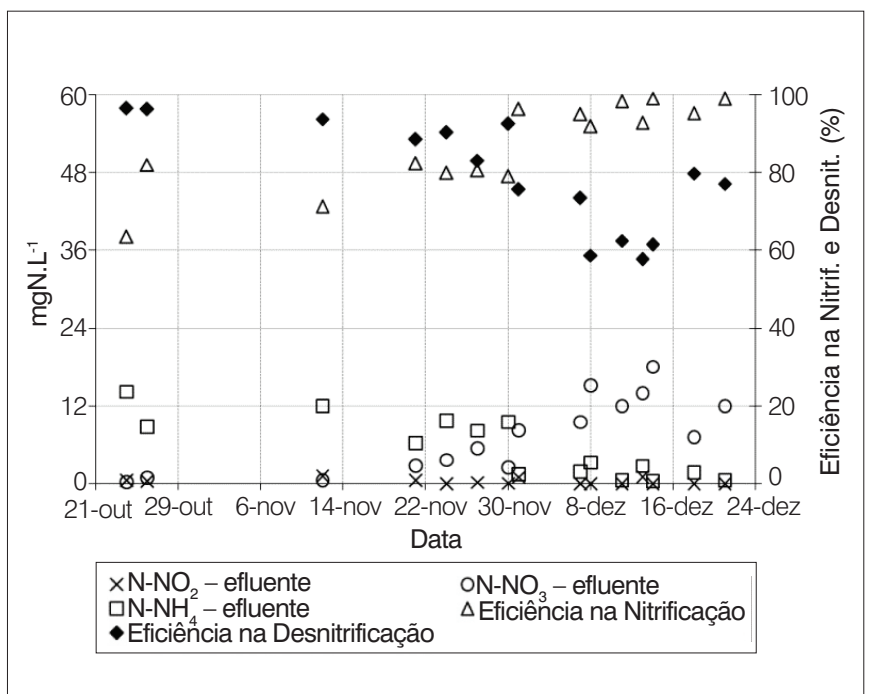

Figura 5 - $\mathrm{N}-\mathrm{NH}_{4}-$, $\mathrm{N}-\mathrm{NO}_{2}$ - e N-NO - efluente e eficiências de nitrificação e desnitrificação (Etapa III). 
apresentados os resultados dos compostos de nitrogênio $\left(\mathrm{N}_{-} \mathrm{NH}_{4}^{-}\right.$,

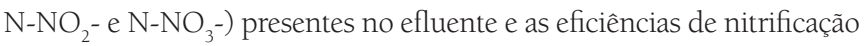
e desnitrificação.

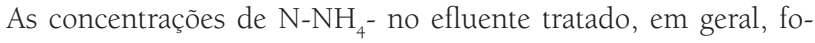
ram inferiores a $10 \mathrm{mg} . \mathrm{L}^{-1}$ (Figura 5). A partir do dia 21 de novembro, verificam-se valores crescentes de $\mathrm{N}_{-} \mathrm{NO}_{3}$ - no efluente tratado, alcançando $30 \mathrm{mg} . \mathrm{L}^{-1}$ em alguns períodos, enquanto as concentra-

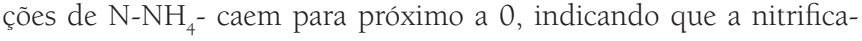
ção ocorreu de forma mais completa, com valores de eficiência de nitrificação acima de 90\%. Como consequência, os valores de nitrato foram mais expressivos no final das fases aeróbias e, mesmo com a desnitrificação ocorrendo na fase anóxica, houve um acúmulo gradual de nitrato ao longo do ciclo que comprometeu a qualidade do efluente final. Durante os ciclos, a alcalinidade foi consumida nas fases aeróbias, devido à liberação do íon $\mathrm{H}^{+}$no processo de nitrificação (ANDREOTTOLA et al., 2005). Como pode ser visualizada na Figura 6, a alcalinidade foi recuperada por meio da desnitrificação durante as fases anóxicas. Observou-se também, para os resultados de $\mathrm{pH}$, a ocorrência do "vale da amônia" nas fases aeróbias.

\section{Remoção de fósforo}

$\mathrm{Na}$ Etapa I, a concentração média de fosfato $\left({\mathrm{P}-\mathrm{PO}_{4}^{-}}^{-}\right)$no esgoto bruto foi de $22 \pm 8,0 \mathrm{mg} / \mathrm{L} \mathrm{L}^{-1}$ e a eficiência média de remoção foi de $44 \pm 31 \%$. Em alguns ciclos, as concentrações no efluente tratado foram maiores que no esgoto bruto, isto ocorre porque bactérias facultativas, que removeram o fósforo solúvel na fase aeróbia, liberaram na fase anóxica tanto a quantidade de fósforo captada no afluente quanto o já acumulado no ciclo anterior. Esse fenômeno é chamado de relargagem de fósforo, que ocorreu devido ao estresse causado pelo aumento de

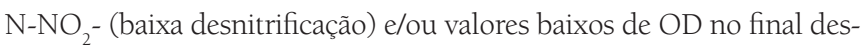
ses ciclos. Esse comportamento tem sido relatado por diversos autores em pesquisas sobre desfosfatação biológica (JU; HUANG; TRIVERDI, 2007) com reatores anóxicos/aeróbios (RBS), nos quais o fenômeno é atribuído à atividade dos organismos fósforo-acumuladores, submetidos a condições de estresse anaeróbio (WU et al., 2009).

Os resultados obtidos para o $\mathrm{P}_{-} \mathrm{PO}_{4}$ - e a DQO, em um ciclo padrão, podem ser visualizados na Figura 7. Nas fases anóxicas, a DQO foi consumida e o fosfato apresentou um aumento ao longo da fase, indicando uma liberação deste pelas bactérias fósforo-acumuladoras (BFA), devido às condições de baixo OD. Como foi observado anteriormente, nessa etapa, durante as fases anóxicas dos ciclos, a presença de nitrato foi quase nula e a concentração de OD foi próxima a 0. Durante as fases aeróbias houve uma queda na concentração de fosfato, devido à assimilação deste (liberado na fase anóxica) por BFA (MACHNICKA; GRÜBEL; SUSCHKA, 2008).

$\mathrm{Na}$ Etapa II, a eficiência média de remoção de $\mathrm{P}_{-} \mathrm{PO}_{4^{-}}$foi de $60 \pm 11 \%$, respectivamente, superiores àquelas obtidas na Etapa I. Isso pode ser explicado pela ausência de nitrato nas fases anóxicas devido

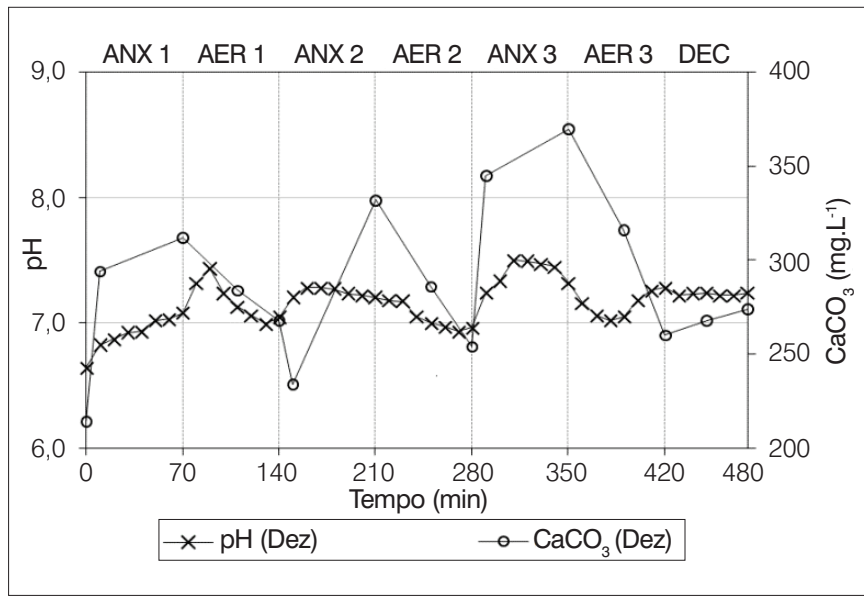

Figura 6 - Alcalinidade e pH ao longo de um ciclo padrão (Etapa III).

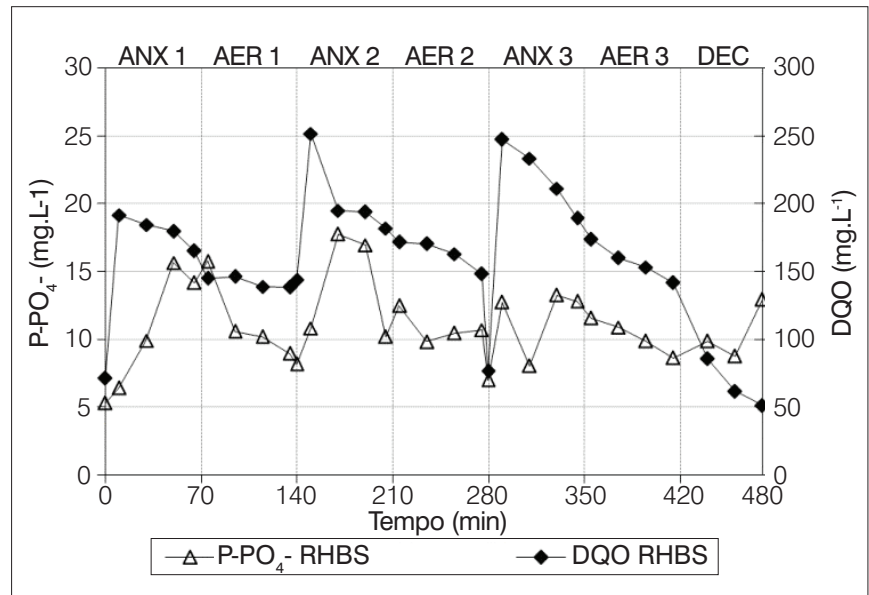

Figura 7 - $\mathrm{PO}_{4}-\mathrm{P}$ e DQO em um ciclo padrão (Etapa I).

à baixa nitrificação e à alta desnitrificação, conferindo zonas anaeróbias nessas fases, e a alta relação DQO/NTK, em torno de 23 (HENZE et al., 2001), decorrente do aumento da carga. A concentração média de $\mathrm{P}_{-} \mathrm{PO}_{4}$ - no efluente tratado foi de 7,1 2 2,1 mg. $\mathrm{L}^{-1}$.

$\mathrm{Na}$ Etapa III, a concentração média de $\mathrm{P}_{-} \mathrm{PO}_{4}$ - no esgoto tratado foi de 8,0 $\pm 5,1 \mathrm{mg} \cdot \mathrm{L}^{-1}$, semelhante aos resultados obtidos na Etapa II. Nas fases anóxicas, o fósforo teve um aumento na concentração, resultado da liberação do fosfato pelas bactérias. Nas fases aeróbias observou-se uma queda do fósforo devido à assimilação do fosfato. A eficiência média de remoção de $\mathrm{P}_{-} \mathrm{PO}_{4}$ - foi de $48 \pm 36 \%$. Na Figura 8 estão apresentadas as concentrações afluentes e efluentes do $\mathrm{P}_{-} \mathrm{PO}_{4}$-e respectivas eficiências de remoção. Observa-se uma queda na eficiência de remoção no final da etapa, como consequência do acúmulo de nitrato no reator, resultante da nitrificação intensa nesse período. Para Henze et al. (2001), isso se explica devido à utilização do carbono orgânico para reduzir o nitrato, diminuindo a disponibilidade deste para os organismos acumuladores de fósforo. Resultados similares foram obtidos por outros autores relatados em Ju, Huang e Triverdi (2007) e confirmam os resultados obtidos por Costa (2005) em reator RBS convencional para o esgoto testado na presente pesquisa. 


\section{Biomassa em suspensão e fixa}

$\mathrm{Na}$ Etapa I, verificou-se a presença de micro-organismos indicadores de estabilidade biológica do lodo, com boa remoção de matéria orgânica e ocorrência de nitrificação, entre eles, principalmente, Arcellas sp, Rotiferos sp e Aspidisca sp. No suporte fixo observou-se um biofilme denso e com presença de muitas Amebas e Rotíferos em sua superfície, indicando um sistema estável e boas eficiências na oxidação da matéria orgânica e na nitrificação (CANLER et al., 1999; HOFFMANN, 2004).

Nos resultados obtidos com a análise FISH, para amostra de lodo e do biofilme para a Etapa I, observou-se que, em ambos os meios, as bactérias eram $40 \%$ oxidadoras de amônio (BOA), do tipo Nitrosomonas sp e Nitrosococcus mobilis, e 15\% no lodo e 5\% no biofilme eram as oxidadoras de nitrito (BON), do tipo Nitrobacter sp. Além destas, foram identificadas também as $\beta$-proteobactérias, que são os principais grupos de micro-organismos envolvidos na remoção do fósforo (WU et al., 2009). A presença desses organismos autotróficos indicam que as condições de $\mathrm{pH}, \mathrm{OD}$ e idade do lodo, foram favoráveis para o crescimento destes micro-organismos, essenciais à oxidação da amônia em nitrito e nitrato (RITTMANN e McCARTY, 2001; DIONISI et al., 2002).

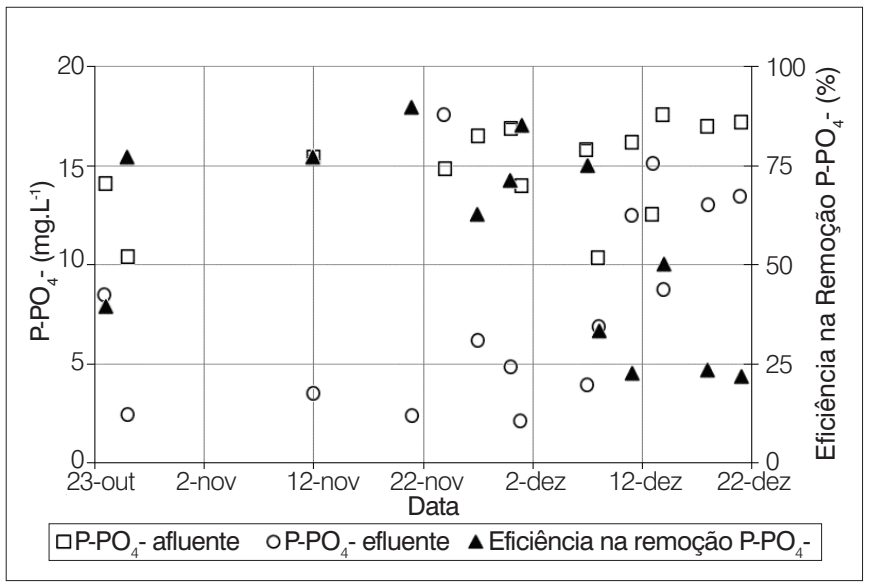

Figura 8 - $\mathrm{P}-\mathrm{PO}_{4}$ - afluente, efluente e eficiência de remoção (Etapa III).
Para amostras de lodo e do biofilme coletadas na primeira semana da Etapa II, os resultados obtidos com a análise FISH revelaram que 70\% das bactérias estavam ativas (eubactérias) no lodo e 80\% no biofilme do suporte fixo, semelhantes à Etapa I. Foram identificadas BOA, do tipo Nitrosomonas sp e Nitrosococcus mobilis sendo $60 \%$ presentes no lodo e 30\% no biofilme. Além destas, foram identificadas também as $\beta$-proteobactérias. As BON, do tipo Nitrobacter sp, apareceram em $20 \%$ no lodo e $15 \%$ no biofilme.

O aumento de carga na entrada do reator durante a Etapa II promoveu o rápido e contínuo crescimento de micro-organismos no lodo, que prejudicou a transferência de OD e a sedimentação do lodo. Nos últimos dias da Etapa II, verificou-se no lodo flocos mal estruturados e destruídos. O efluente do RHBS apresentava turbidez e espuma no sobrenadante, devido à perda de biomassa do reator, com menor diversidade e quantidade de micro-organismos, indicando o desequilíbrio na microfauna do lodo. Quanto ao biofilme fixo no material suporte, as observações microscópicas revelaram mudanças em sua composição: este se apresentou pouco denso e mal estruturado, com algumas Vorticellas sp.

Esse comportamento pode ser confirmado também pela queda de eficiência de remoção de matéria orgânica (DBO e DQO) e nitrogenada (N-NH $4_{4}^{-}$, nessa etapa, e pelo aumento das concentrações de SST no efluente do RHBS. Por meio do FISH, observou-se a presença de muito material extracelular na amostra de lodo e pouco na amostra de biofilme, devido à destruição dos flocos e enfraquecimento da biomassa fixa.

Na Etapa III, observou-se no lodo flocos compactos e bem formados (Figura 9), resultado da recuperação do equilíbrio biológico do sistema. Nesse período houve a predominância de Arcellas sp e Vorticellas sp. Essas constatações foram confirmadas pelo sobrenadante com baixa turbidez ( $<40$ NTU) e sólidos totais $\left(30 \pm 9\right.$ mgSST.L $\left.{ }^{-1}\right)$ na saída do reator. Utilizando reator híbrido, tendo como material suporte terra diatomácea, Zhao et al. (2006) também obtiveram efluente com baixa turbidez ( 8 NTU).
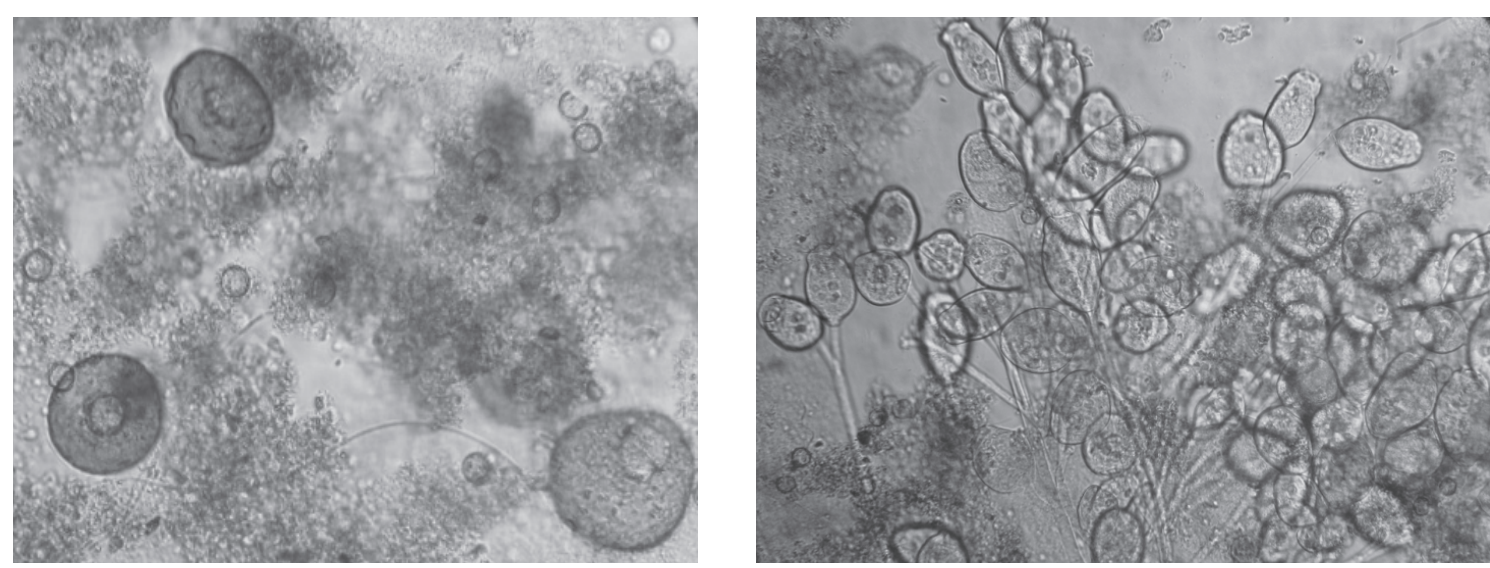

Figura 9 - Arcellas sp e Vorticellas sp, respectivamente, no lodo do RHBS - microscópio ótico 100X (Etapa III). 


\section{Conclusões}

O RHBS realizou o tratamento de efluente urbano em uma única unidade operacional, compacta e com operação simplificada e estável, tratando eficazmente as diferentes cargas aplicadas carbonácea (DBO, DQO) e de nutrientes (N, P). Quanto a remoção de SST e DQO o reator apresentou eficiência em torno de $80 \%$, enquanto que para a $\mathrm{DBO}_{5}$ a eficiência média foi de $92 \%$. Os processos de nitrificação e desnitrificação foram verificados ao longo da pesquisa, resultando na remoção de nitrogênio total, com eficiência variando entre 59 e $71 \%$. Nas fases aeróbias foi verificado também o consumo da alcalinidade e queda do $\mathrm{pH}$, característico "vale da amônia", e nas fases anóxicas observou-se a recuperação da alcalinidade. Houve também remoção de fósforo em grande parte dos ciclos, porém, com eficiência menor que variou entre 45 e $67 \%$.
A análise FISH demonstrou que $70 \%$ das bactérias estavam ativas (eubactérias) no lodo e $80 \%$ no biofilme do suporte fixo. Nos dois meios, essas bactérias eram 40 a 60\% BOA (Nitrosomonas spp e Nitrosococcus mobilis); cerca de 15 a 20\% no lodo e 5 a 15\% no biofilme eram BON (Nitrobacter spp). Isso implica uma atividade microbiana maior no reator, envolvendo organismos de lento e de rápido crescimento.

Portanto, o enchimento escalonado e a presença de maior atividade microbiana no sistema híbrido possibilitaram uma maior flexibilidade e estabilidade quanto à variação de cargas afluente, além de maior eficiência na remoção de nutrientes, quando comparado com lodo ativado convencional.

\section{Agradecimento}

Os autores agradecem ao Conselho Nacional de Desenvolvimento Científico e Tecnológico (CNPq) pela bolsa de estudos.

\section{Referências}

AMANN, R.I. In situ identification of microorganisms by whole cell hybridization with rRNA-targeted nucleic acid probes. In: AKKERMANS A.D.L.; van ELSAS J.D.; de BRUIJN, F.J. (Eds). Molecular microbial ecology manual. London: Kluwer Academic Publications, 1995. p. MMEM-3.36/1-MMEM-3.3.6/15.

ANDREOTTOLA, G.; FOLADORI, P.; NARDELLI, P. et al. Treatment of winery wastewater in a full-scale fixed bed biofilm reactor. Water Science and Technology, v. 51, n. 1, p. 71-79, 2005.

APHA; AWWA; WEF. Standard methods for the examination of water and wastewater. 21 $1^{\text {th }}$ ed. Washington, DC: APHA, AWWA, WEF, 2005.

ARTAN, N.; ORHON, D. Mechanism and design of sequencing batch reactors for nutrient removal. Scientific and Technical Report Series, 19. London: IWA Publishing, 2005.

CALLADO, N.H., FORESTI, E. Remoção biológica de fósforo em reator sequencial em batelada tratando esgoto sanitário sintético utilizando acetato como fonte externa de carbono. In: XXVIII CONGRESO INTERAMERICANA DE INGENIERIA SANITARIA Y AMBIENTAL. Anais... Cancun: AIDIS/ABES, 2002

CANLER, J.P.; COTTEUX, E.; DUCHÈNE, P. et al. Aide ou diágnostic des stations d'épuration par l'observation microscopique des boues activées. France: CEMAGREF, 1999.

COSTA, T.B. Desempenho de reator em batelada seqüencial (RBS) com enchimento escalonado no tratamento de esgoto sanitário doméstico. 2005. 105f. Dissertação (Mestrado em Engenharia Ambiental) Universidade Federal de Santa Catarina, Florianópolis, 2005.

DIONISI, H.M.; LAYTON, A.C.; ROBINSON, K.G. et al. Quantification of Nitrosomonas oligotropha and Nitrospira spp. using competitive polymerase chain reaction in bench-scale wastewater treatment reactors operating at different solids retention times. Water Environment Research, v. 74, n. 5 , p. $462-469,2002$

HENZE, M. et al. Wastewater treatment: biological and chemical processes. Springer Verlag. Second Edition. Heidelberg, 1995.

HENZE, M.; HARREMOËS, P.; LA COUR JANSEN, J. et al. Wastewater treatment: biological and chemical processes. Berlin: Springer, 2001.

HOFFMANN, H. Caracterização do funcionamento de ETE do tipo lodo ativado via imagem microscópica - estudo na Região da Grande Florianópolis. In: XI SIMPÓSIO LUSO-BRASILEIRO DE ENGENHARIA SANITÁRIA E AMBIENTAL - SILUBESA. Anais, ABES, Natal, RN, 2004. CD ROM.

HOFFMANN, H.; COSTA, T.B.; WOLFF, D.B. et al. The potential of denitrification for the stabilization of activated sludge processes affected by low alkalinity problems. Brazilian Archives of Biology and Technolog, v. 50, n. 2, p. 329-337, 2007.

JU, L.K.; HUANG, L.; TRIVERDI, H. Simultaneous nitrification, denitrification, and phosphorus removal in single-tank low-dissolvedoxygen systems under cyclic aeration. Water Environment Research, v. 79, n. 8. p. 912-920, 2007.

LEVSTEK, M.; PLAZL, I. Influence of carrier type on nitrification in the moving-bed biofilm process. Water Science and Technology, v. 59, n. 5, p. $875-882,2009$

LIN, Y.F; JING, S.R. Characterization of denitrification and nitrification in a step-feed alternating anoxic-oxic sequencing batch reactor. Water Environment Research, v. 73, n. 5, p. 526-533, 2001

MAAS, C.L.; PARKER, W.J.; LEGGE, R.L. Detachment of solids and nitrifiers in integrated, fixed-film activated sludge systems. Water Environment Research, v. 80, n. 12, p. 2202-2208, 2008. 
MACHNICKA, A.; GRÜBEL, K.; SUSCHKA, J. Enhanced biological phosphorus removal and recovery. Water Environment Research, v. 80, n. 7, p. 617-623, 2008.

METCALF \& EDDY. Wastewater engineering: treatment and reuse. $4^{\mathrm{a}} \mathrm{Ed}$. New York: Mc Graw Hill, Inc., 2003.

$\varnothing \mathrm{DEGAARD}, \mathrm{H}$. Innovations in wastewater treatment: the moving bed biofilm process. Water Science and Technology, v. 53, n. 9, p.17-33, 2006.

PAUL, E.; WOLFF, D.B.; OCHOA, J.C. et al. Recycled and virgin plastic carriers in hybrid reactors for wastewater treatment. Water Environment Research, v. 79, n. 7, p. 765-774, 2007.

RITTMANN, B.E.; McCARTY, P.L. Environmental biotechnology: principles and applications. New York: McGraw-Hill, 2001.

SANTOS, A.S. Comportamento do reator seqüencial em batelada (RSB) sob estado estacionário dinâmico utilizando a idade do lodo como parâmetro de controle operacional. 206 p. Tese (Doutorado em Recursos Hídricos e Saneamento Ambiental). Instituto de Pesquisas Hidráulicas da Universidade Federal do Rio Grande do Sul, Porto Alegre, 2005.

SANTOS, A.V.; CYBIS, L.F.A.; GEHLING, G.R. Balanço de massa no reator seqüencial em batelada (RSB) sob diferentes idades de lodo. In: $23^{\circ}$ CONGRESSO BRASILEIRO DE ENGENHARIA SANITÁRIA E AMBIENTAL, Campo Grande. Anais... ABES, 2005. 1CD.
SOUTO, V.S. Utilização de reatores híbridos de fluxo contínuo e em bateladas seqüenciais para remoção conjunta de carbono e nitrogênio de esgoto urbano. 2007. 204f. Dissertação (Mestrado em Engenharia Ambiental) - Universidade Federal de Santa Catarina, Florianópolis, 2007.

UNITED STATES ENVIRONMENTAL PROTECTION AGENCY, EPA. Manual Nitrogen Control. Technomic Publishing. Washington, USA, 1993.

VON SPERLING, M. Lodos ativados. 2a ed. ampliada. Belo Horizonte: Departamento de Engenharia Sanitária e Ambiental (DESA), Universidade Federal de Minas Gerais (UFMG), vol. 4, 2002.

WOLFF, D.B; PAUL, E.; COSTA, R.H. Reatores híbridos: uma nova alternativa para o tratamento de efluentes. Saneamento Ambiental, $v$. 111, p. 30-33, 2005.

WU, G.; S RENSE, K.B.; RODGERS, M. et al. Microbial community associated with glucose-induced enhanced biological phosphorus removal. Water Science and Technology, v. 60, n. 8, p. 2105-2113, 2009.

YE, L.; TANG, B.; ZHAO, K.F. et al. Nitrogen removal via nitrite in domestic wastewater treatment using combined salt inhibition and on-line process control. Water Science and Technology, v. 60, n. 6, p. 1633-1639, 2009.

ZHAO, Y.; CAO, D.; LIU, L. et al. Municipal wastewater treatment by moving-bed-biofilm reactor with diatomaceous earth as carriers. Water Environment Research, v. 78, n. 4, p. 392-396, 2006 